\title{
THE
}

\section{Engaging Donors in Smart Compassion: USAID CIDI's Greatest Good Donation Calculator}

Koray Özpolat

University of Rhode Island, koray@uri.edu

Juanita Rilling

Nezih Altay

Eric Chavez

Follow this and additional works at: https://digitalcommons.uri.edu/cba_facpubs

The University of Rhode Island Faculty have made this article openly available. Please let us know how Open Access to this research benefits you.

This is a pre-publication author manuscript of the final, published article.

Terms of Use

This article is made available under the terms and conditions applicable towards Open Access Policy Articles, as set forth in our Terms of Use.

Citation/Publisher Attribution

Koray Özpolat, Juanita Rilling, Nezih Altay, Eric Chavez, (2015) "Engaging donors in smart compassion: USAID CIDI's Greatest Good Donation Calculator", Journal of Humanitarian Logistics and Supply Chain Management, Vol. 5 Iss: 1. Available:

http://www.emeraldinsight.com/doi/abs/10.1108/JHLSCM-11-2013-0041 


\section{Introduction}

Dozens of natural and human-caused disasters occur across the globe every year resulting in extensive social and economic devastation (Guha-Sapir et al., 2013). The U.S. Agency for International Development (USAID) Office of U.S. Foreign Disaster Assistance (OFDA) having a mandate to save lives, alleviate human suffering and reduce the economic and social impact of humanitarian emergencies worldwide - responds to an average of 70 international disasters in more than 50 countries every year. While disasters differ in location, magnitude and damage, they frequently have one thing in common that causes serious problems for relief organizations - unsolicited material donations. As a result, USAID created the Center for International Disaster Information (USAID CIDI), and charged the Center with informing the American public about the most effective and appropriate ways to help international disaster survivors, in an effort to reduce the amount of unsolicited material donations sent to disaster relief efforts overseas. To this end, USAID CIDI developed an online donations calculator in collaboration with the University of Rhode Island to inform donors about the inefficiencies and problems non-monetary contributions can create. In this case study, we introduce the "Greatest Good Donation Calculator (GGDC)" to the humanitarian logistics community as a useful online tool to improve participatory learning and dialogue between stakeholders of humanitarian relief chains.

After a large scale disaster, local governments, law enforcement, armed forces, emergency response teams, NGOs, charities and volunteers alike rush to the incident site creating a “convergence" of goods, people and information (Fritz and Mathewson, 1957). While this arrival of much-needed help is frequently welcome by the impacted communities, a speedy and smooth delivery of assistance is often hindered by the "traffic jam" created by unsolicited goods and 
volunteers. Not only are NGOs and relief agencies sometimes compelled to transport unsolicited goods domestically and ship to disaster sites, but many highly motivated individual donors pay exorbitant fees to ship unsolicited donations to disaster sites overseas, by air and by sea, frequently without a consignee. For example, in the aftermath of the 2010 Haiti earthquake, "large quantities of donations from the public addressed to The People of Haiti arrived at the already congested airport" (Besiou et al., 2011, pp. 93). This further disrupted the strained humanitarian operations on the ground.

The general population is typically unfamiliar with what goes into a humanitarian response operation and may think that their donated goods - though unsolicited - will help the affected population. However, the reality in the field is that these goods take up valuable time and scarce human resources to unload, sort, store and distribute, or dispose of. Once unloaded from a plane or ship, these donations sit in staging areas, occluding space needed to stage life-saving supplies. They usually need to be moved aside, which takes relief workers' time and frequently requires heavy equipment. Resources devoted to this purpose are drawn at the expense of attention to survivors and programs that support them. In some cases, these unwanted, inappropriate and generally unusable goods make up a majority of the total materials donated. For example, unwanted goods constituted $95 \%$ of all goods received in the wake of the 1993 earthquake in Bangladesh (Chomilier et al., 2003). Unfortunately, the Bangladesh case is not an exception as anecdotal evidence of inappropriate, expired, or unwanted donations is plentiful (Altay, 2008; Holguin-Veras et al., 2012).

The problem is so serious that disaster responders call it "the second disaster" (Newsweek, 2002). Still, humanitarian aid organizations are sometimes unwilling to reject unsolicited donations for fear of upsetting donors and potentially losing future funding (Holguin-Veras et 
al., 2012). However, there is growing push in the humanitarian community for cash donations as money gives these organizations important flexibility in their operations (Harvey and Bailey, 2011). The general public on the other hand, partially due to unfamiliarity with the sector and partially due to questions about individual NGO's financial transparency, can be reluctant to donate cash. Public reactions to a recent article by long-time humanitarian worker Jessica Alexander highlight the fact that the donor community is still concerned about how their money will be used by relief organizations (Jessica Alexander, 2013). While humanitarian workers applauded her efforts in educating donors about the disadvantages of donating unsolicited goods, or in her words "cleaning out their closet" or garage, the public's reaction to the piece demonstrates the need for additional public engagement through educational tools like the GGDC (Alexander, 2013).

In this paper, the GGDC is introduced to the academic and professional humanitarian logistics community as an online participatory learning tool developed to educate the American public about the real cost of shipping and handling material items overseas. The literature in human learning and systems dynamics has been used as theoretical basis for the calculator. Humanitarian logistics is presented as a complex system that is shaped by the interaction of multiple stakeholders with diverse motivations. The GGDC is further positioned as a game-like decision tool that helps improve human learning of a complex mechanism in humanitarian logistics (i.e., unsolicited material donation as aid to international disasters). The GGDC demonstrates to the user that the value of items commonly donated to disaster relief efforts, in U.S. dollars, is comparatively less than the overall cost of shipping those items internationally, and as such fails to justify the logistics costs of sending them to a disaster-affected country. Using the GGDC, an individual donor can see how much it will cost to ship a certain good (e.g., 
a pair of jeans, a teddy bear...) directly to a given destination. The calculator then adds the monetary value of the good to the shipping cost and compares this total cost with what the same amount of money could purchase as a cash donation to a charitable organization and how many survivors would be served with that cash donation in the disaster-affected country. Consequently, the inefficiencies of sending material donations as relief aid to international disasters are made visible to the donors, which may encourage them to donate cash instead.

The rest of the paper is structured as follows: In section 2, we introduce the context of the case study and thoroughly discuss the problem that GGDC intends to address - unsolicited material donations. Section 3 provides a review of the relevant literature in human learning, games and data-based decision tools. Sections 4 and 5 introduce the GGDC as a successful outcome of USAID CIDI's efforts to encourage effective forms of donations. We conclude in section 6 by providing a summary of the GGDC's value as a decision-aid tool to inform individual donors.

\section{Context of the case study: unsolicited material donations}

Logistics is critical to the success of disaster relief. In his Blackett Memorial Lecture, Van Wassenhove (2006, pp. 475) states that, "Since disaster relief is about $80 \%$ logistics it would follow then that the only way to achieve this [more effective disaster relief operations] is through slick, efficient and effective logistics operations and more precisely, supply chain management." Though seldom evaluated by scholars researching the topic of humanitarian logistics, the impact that donors have on disaster relief operations can be highly significant. However, one of the greatest challenges to humanitarian logistics during a disaster relief operation comes in the form of unsolicited material donations. Hence, it is very important to raise public awareness about the hazards of unsolicited material donations and encourage individual and organizational donors to give monetary contributions in response to international disaster relief efforts instead. 


\subsection{Monetary vs. material donations in response to international disasters}

The effect that monetary and material donations have on a disaster relief operation is best evaluated by comparing their respective impacts on the humanitarian supply chain. The humanitarian supply chain is a vital function of a disaster relief effort because it is the mechanism by which relief organizations acquire and distribute goods and services to disasteraffected people. In this respect, the humanitarian supply chain is similar to a private sector supply chain because both describe "a set of three or more entities (organizations or individuals) directly involved in the upstream and downstream flows of products, services, finances, and/or information from a source to a customer" (Mentzer et al., 2001, pp. 4). In the case of a disaster relief operation, the customers are the disaster-affected population, and the sources could range from individual donors to private businesses, governments, etc., with relief organizations acting as intermediaries between these two parts of the supply chain.

Different phases of a disaster relief operation favor different qualities in a humanitarian supply chain, and while scholars debate these phases and their relative goals, the most commonly agreed upon phases are Mitigation, Preparation, Response, and Reconstruction (Cozzolino, 2012). Donations primarily impact the Response and Reconstruction phases, and the way in which donors choose to contribute to disaster relief efforts can dramatically influence the effectiveness of a disaster relief operation because of the logistical implications they place on relief organizations.

The Response phase of a disaster relief operation occurs immediately after the onset of a disaster (Cozzolino, 2012), during which the first 72 hours are considered to be crucial. This forces relief organizations to favor speed over all else (Van Wassenhove, 2006). In the wake of a natural disaster, such as the 2010 Haiti Earthquake, substantial loss of life can occur and be 
exacerbated by sluggish relief operations. This adds the pressure of time constraints on relief organizations that can mean the difference between life and death for disaster-affected people (Van Wassenhove, 2006).

While evaluating supply chains operating in volatile markets, particularly in the auto industry, Christopher (2000, p. 38) asserts that, "[a]gility is needed in less predictable environments where demand is volatile and the requirement for variety is high." Disaster relief operations, particularly in their early stages, are conducted in a highly volatile environment where the needs of the disaster-affected population can be unpredictable, and may change frequently (Oloruntoba and Gray, 2006). Unsolicited material donations can disrupt the humanitarian supply chain because they are provided by donors that, while well-intentioned, are generally unaware of changing needs on the ground, and as a result, may fail to match up (Van Wassenhove et al., 2010). This causes logistical problems that severely reduce the agility of the humanitarian supply chain, delaying distribution of needed goods and services to disaster-affected people.

As a disaster relief operation transitions from the Response phase to the Reconstruction phase, the goals of the operation shift from being short-term in nature to long-term (Cozzolino, 2012). For logisticians working in disaster relief management, this translates into a shift in focus from speed to cost savings (Tomasini and Van Wassenhove, 2009). Relief organizations begin to experience responder fatigue, reduced funding, and other logistical barriers that place increased pressure on logisticians to do more with less; a quality in the manufacturing industry that is generally referred to as "leanness" (Cozzolino, 2012).

Here again, unsolicited material donations have a disruptive influence on a humanitarian supply chain by reducing its capacity for cost-savings, or, "leanness". Not only do they take time away from relief workers, whose staffs may be waning, the additional cost of warehousing and 
transportation for unplanned and unneeded items severely cuts into the limited resources available to relief organizations working in the field.

Conversely, monetary donations assist logisticians by increasing the effectiveness of the humanitarian supply chain, whether its current focus is on agility, leanness or both. Monetary donations enable relief organizations to purchase supplies that directly correspond with changing needs on the ground while enabling logisticians to more effectively plan storage, transportation, and delivery of supplies. This dramatically increases the capability of relief organizations to control costs, and quickly provide needed goods and services to disaster survivors.

\subsection{Logistics of handling material donations}

Logisticians working in disaster relief management are responsible for planning how relief operations are carried out (Van Wassenhove, 2006), including the preparation of proper storage, transportation, and distribution of materials received. Unsolicited material donations are by definition, unplanned, and force relief organizations to divert resources intended for planned inventory materials to the storage, transportation and distribution of unplanned materials.

After the 2004 Indian Ocean Tsunami, large-scale relief efforts were made in the disasteraffected countries of Southeast Asia. However, a report by the Fritz Institute that surveyed over 350 non-governmental organizations (NGOs) working in India and Sri Lanka during the tsunami recovery effort found that, "[h]igh levels of unsolicited in-kind donations-reported by $61 \%$ of surveyed NGOs in India, and $41 \%$ in Sri Lanka-further eroded warehousing and transshipment capacity. In some instances, warehousing and transportation shortfalls combined with oversupply of goods created critical logistical bottlenecks, which in turn forced the unwanted disbursement of aid materials" (Fritz Institute, 2005, pp.3). Due to the limited availability of resources such as warehousing space, available staff, and the time relief workers must devote to sorting through 
donated items, unsolicited material donations often cause "bottlenecking" in humanitarian supply chains (Stapleton et al., 2010). Bottlenecks delay the provision of goods and services by relief organizations, and hinder their ability to quickly respond to the changing needs of disasteraffected population.

In places like Sri Lanka, all types of unusable materials, including winter hats, thong underwear, cologne, and women's dress shoes arrived only to strain relief workers who deemed them "frustrated cargo" because of the logistical problems they posed to relief organizations working in the region. "Mounds of donated clothes litter the coastal highway south of Colombo. Bottled water from European mountain streams is flowing freely, raising concern about litter in the jungle. Medicines that are no longer needed, such as morphine, are feared to be loose in the country. Paradoxically, many vital needs still aren't being met, even as pointless donations pile up" (Bart and Bellman, 2005, para. 3, 6).

Similarly, between 1992 and 1996, large quantities of medical supplies totaling between 27,800 and 34,800 tons were donated to Bosnia in support of ongoing relief efforts there. Of the materials sent, approximately 17,000 tons consisted of expired medications and other unneeded supplies and were deemed unusable. The cost of disposal for these unusable medical donations amounted to approximately $\$ 34$ million (Berckmans et al., 1997). This figure exclusively represents the cost of disposal, and does not include the cost of transportation and delivery, or the hours spent sorting through these medications to identify them and determine their expiration dates. Moreover, $\$ 34$ million could have been more constructively applied to needs of disasteraffected people, as opposed to alleviating this "second disaster".

Another risk of sending material donations to a disaster-affected country is that the donations may never reach the disaster-affected area. Depending on the recipient country's customs 
policies, material donations could languish in a local customs office indefinitely, which can result in a sizable bill for storage to relief organizations attempting to retrieve them. Two years after the 2004 Indian Ocean Tsunami, an estimated 217 containers of aid remained sitting in Tanjung Priok Port outside Jakarta, while an additional 232 containers of supplies and 58 vehicles remained sequestered in Belawan Port, Medan (Diani, 2006).

When material donations are actually delivered to the disaster-affected area, they require space to be securely stored, individually sorted by relief workers, and, if determined to be useful and in sufficient quantity, distributed to the disaster-affected population. Distribution requires intense logistical planning, including considerations for relief supply allocation, vehicle delivery scheduling, vehicle routing and safety. This can be further complicated by a damaged transportation infrastructure and limited transportation resources (Balcik et al., 2008). Given these considerations, unplanned, unsolicited material donations further complicate both the inventory management and distribution processes for relief organizations. Despite all the above discussed risks and inefficiencies, many donors still prefer to donate unsolicited goods to international disasters which makes "donor education" an important issue.

Humanitarian supply chains are complex systems and individual donors often find it challenging to see the big picture and make effective donation decisions. We ground our case study in the human learning and complex systems literature, as discussed next in section 3.

\section{Human learning through games and data-based decision tools}

\subsection{Learning in complex systems: A systems dynamics perspective}

Human learning significantly depends on feedback received after making a decision and acting on it (Sterman, 1994). The negative consequences of our actions motivate us to adjust/change our prior actions and also evaluate our mental models to better reach our goals in the future. 
However, the path to learning through feedback is challenged by many barriers in complex dynamic systems. In real life there is often a delay between an action and its consequences which is not fully accounted for by many decision makers. For example, the delay (lead time) between placing and receiving an order is a cause of the bullwhip effect (i.e., amplification of variability as orders move upstream in the supply chain) in the beer distribution game. When these delays are long, humans find it difficult to link their actions to the consequences which hinder learning. Other barriers to learning through feedback include the limited and imperfect information, confounding factors, ambiguity, and poor reasoning and inquiry skills of humans.

To improve learning in complex systems, Sterman (1994) suggests that decision-makers experiment regularly, not only in real life but also in "virtual worlds", which he defines as "formal models or microworlds in which decision makers can refresh decision making skills, conduct experiments and play" (pp. 317). By compressing the time and space, virtual worlds allow the decision maker to experience and learn more in a relatively short period. Simulations, role plays and games are examples of learning in virtual worlds, which are commonly used to teach trainees how to interact with complex systems. Focusing on serious games, Harteveld and Bidarra (2007) present a case study of the "Levee Patroller" game and suggest that games could "foster learning in professional environments" (pp. 555). In other settings, airlines use simulations to train pilots (e.g., flight simulators), militaries use simulations and games to teach war strategy (e.g., Marine Doom), advocacy groups use games (e.g., Half the Sky) as a catalyst for social change (Sydell, 2013), and management educators use games to teach decision making, team work and leadership (Keys and Wolfe, 1990; Lane, 1995) 


\subsection{Learning in humanitarian operations}

Humanitarian operations are complex systems "characterized by multiple actors, feedback loops, time pressures, resource constraints and uncertainty" (Besiou et al., 2011, pp.78). Multiple stakeholders, such as local and international humanitarian organizations, private sector companies, governments, military and individuals are involved, which makes coordination challenging. Humanitarian organizations have multiple objectives of short-term relief and longterm development financed by funds often earmarked for particular programs which further complicates decision making (Besiou et al., 2011). Finally, humanitarian organizations function under uncertain and dynamic conditions. There is a high degree of uncertainty and change in supply (donations) and demand (number and needs of beneficiaries) levels. For example, unsolicited donations arrive in varying types and quantities, most of which are not needed in the disaster area. There is also much uncertainty in available human resources, usable infrastructure, and political situations (especially after man-made disasters, such as civil strife) in and around recipient countries (Tomassini and Van Wasenhove, 2009). Therefore, stakeholders of this complex environment (e.g., humanitarian professionals and donors) can also learn from games and simulations."

It has been discussed that gaps exist between research and education as well as practice and education in humanitarian logistics (Kovacs and Spens, 2011). Following this research lead, Lu et al. (2013) suggest that one of the ways humanitarian logisticians learn is by doing. Learning is grounded in experience and Experiential Learning Theorist Kolb (1984, pp.41) asserts "Knowledge results from the combination of grasping and transforming experience." Investigating facilitators of experiential learning, Bowen (1987) found that experiential learning has bigger impact when there is a significant emotional stimulus, when the experience takes 
place in a safe environment, and is accompanied by ample processing time along with a clear summary providing a cognitive map for understanding the experience. Additionally, Keys (1989) considers three factors that are essential for effective experiential learning: content (i.e., dissemination of new ideas, principles or concepts); experience (i.e., an opportunity to apply content in an experiential environment); and feedback on the relationship between the actions taken and performance. Next, we discuss how game-like tools can help improve learning in humanitarian operations.

\subsection{Decision making tools and games}

Data-based decision making tools are one form of simulation. They allow the user to test various scenarios and perform "what if" analysis. Keys and Wolfe (1990) define a simulated experimental environment as "a simplified and contrived situation that contains enough verisimilitude or illusion of reality, to induce real world-like responses by those participating in the exercise" (pp. 308). Data-based decision support tools are being used to train medical students on evidence-based medicine (Leung et al., 2003). Similarly, decision support tools such as online mortgage calculators or retirement savings calculators have been used to build consumer literacy in the financial sector (Howlett et al., 2008). At least in the healthcare context, it has been shown that building consumer literacy is critical for implementing policies properly because it increases participation in health care (Protheroe et al., 2009).

As per McGonigal (2011) definition, every game shares the following four characteristics: a goal, rules, a feedback system and voluntary participation. The goal provides players a "sense of purpose" to achieve and "the rules place limitations on how players can achieve the goal" (McGonical 2011, pp.2). The feedback system informs the user about his/her progress towards the goal, and voluntary participation ensures that the player accepts the rules and the activity is 
"safe" and "pleasurable". Based on these four characteristics of a game, we propose that the GGDC is a game-like tool that satisfies all of these characteristics except the first one: (i) the calculator provides the user with a limited number of possibilities. Users pick one of the available 160 "item-origin-destination" combinations (4 items x 4 origin cities x 10 destination cities). (ii) There is a visual feedback system informing the user about the total cost (in U.S. dollars) of shipping the item from the origin to the destination, and number of people in the destination city that would be served with drinking water, blankets or hygiene kits with an equivalent cash donation, and (iii) playing with the calculator is a safe activity with voluntary participation. The GGDC currently does not present a direct goal to the user. However, this could be changed if the GGDC were to have a scoring system that allows the user to guess the total cost of donating an item based on their origin and destination selections prior to calculating the actual cost. Scores would be determined by how close the user's estimation was to the actual cost. In the future, a challenge mode could be added to the GGDC where users can challenge their Facebook friends to estimate the total donation cost of an item-origin-destination combination that they pick. Such an addition would also increase traffic to the site and bring the GGDC closer to its main goal of educating the public about the real cost of unsolicited donations.

We draw a parallel between health literacy and its implications in healthcare with the literacy of donors in the humanitarian sector and its implications in humanitarian logistics. Consequently, the GGDC described in this paper can be considered a game-like training tool to create awareness of logistics costs in the humanitarian sector and educate donors on the merits of making cash donations. It is seemingly a black-box similar to a decision support tool but has game-like aspects that resemble the case of the Blokkendoos, an interactive water management 
tool (Zhou and Mayer, 2010). But what GGDC really aims for is educating the public on the merits of cash donations, similar to what Budget Hero did for the federal budget process. Budget Hero was a computer game that gave users the opportunity to test and recognize the effects of specific budget cuts or expenditures on the federal budget. It has been active from 2008 to 2014 . The GGDC satisfies Bowen's (1987) three experiential learning criteria (emotional stimulus, safe environment, ample processing time), and also covers Keys' (1989) three factors (content, experience and feedback) in a very simple way, thus providing an experiential learning tool to the general public, which is also game-like due to its alignment with the four game characteristics of McGonical (2011).

\section{Encouraging effective forms of donation}

\subsection{USAID/CIDI}

There is a complex logistics system supporting humanitarian supply chains in moving aid from donors to beneficiaries, such as collection, sorting, packing, transportation, storage, customs clearance and last mile distribution; which are rarely observed and known by donors. In 1988, USAID created the Center for International Disaster Information (USAID CIDI) one month after Hurricane Gilbert (a Category 5 storm) made landfall, affecting ten countries in Latin America and the Caribbean. A sustained outpouring of unsolicited donations occluded space needed to stage and deliver life-saving relief supplies, and responders spent valuable time and resources managing unneeded clothing, expired medicine, and other unnecessary items. Hence, USAID CIDI's mission is to educate the American public about the most effective and appropriate ways

to help international disaster survivors. USAID CIDI supports OFDA's mission by engaging and informing the American public in an effort to curb the volume of unsolicited material donations that are sent to disaster relief sites by U.S. donors. 


\subsection{Smart compassion}

Since its inception, USAID CIDI has had decades of experience with disaster relief efforts, donors, and donations. The culmination of experience with research and analysis has led CIDI to conclude that monetary contributions to proven relief agencies give the best support to disasteraffected people. Monetary contributions enable relief organizations and logisticians to operate more effective humanitarian supply chains, which helps to ensure that supplies are fresh and familiar to survivors, that provisions arrive quickly and that goods are culturally, nutritionally and environmentally appropriate. No unsolicited material donation can be as effective as quickly and at such low cost, with as little trouble for donors, recipients and, in the case of international disaster response, affected countries. USAID CIDI regards the act of donating monetarily, instead of in-kind, to disaster relief efforts as "Smart Compassion". CIDI's longstanding "tag line" is "Cash Is Best".

\subsection{Collaborating with academia to educate donors: PSAid contest}

In an effort to expose more Americans to the benefits of Smart Compassion, USAID CIDI collaborates with U.S. colleges and universities on an annual competition called "PSAid" (see Özpolat et al. (2014) for PSAid's application as a semester project in an introductory operations and supply chain management course). This nationwide contest invites students to create 30second video public services announcements (PSAs) or print PSAs with "Cash Is Best" messaging. Entries are judged by a panel of experts in humanitarian assistance and media, and winning entries are broadcast nationally. Since PSAid's inception in 2008, students have helped spread "Cash Is Best" messaging to prospective donors in the United States through visual PSAs. These PSAs have been used by relief agencies to educate the public and raise awareness of the challenges in unsolicited material donations to international disasters. 
While the PSAs help raise public awareness in smart compassion, they are unidirectional in nature and do not allow interaction and dialogue. The need for an interactive online tool to promote smart compassion motivated academics and humanitarian professionals to collaboratively develop the GGDC.

\section{The Greatest Good Donation Calculator}

\subsection{Development of the GGDC}

The GGDC, which was created over the course of a year-long collaboration between USAID CIDI and the University of Rhode Island, went live on www.cidi.org in April 2013. The interdisciplinary URI team consisted of two professors (one business and one computer engineering), and three undergraduate students (two business and one computer engineering) who consulted with staff from CIDI regularly during different phases of the project. The professor and students from the college of business administration worked on the logistical aspects of the calculator, while web design and implementation were performed by the professor and student from the college of computer engineering, and CIDI's web designer.

\subsection{User experience}

The GGDC engages individual U.S. donors in partially experiencing the complex systems behind humanitarian supply chains by informing them about the high costs of shipping material items overseas. Users visiting USAID CIDI's website - www.cidi.org - can navigate to the GGDC by clicking its link located under the tab labeled 'how disaster relief works'. Upon entering the page, the user is presented with a brief description of how the idea for the GGDC came about followed by three dropdown menus labeled 'Item', 'Origin', and 'Destination'. After making desired selections, the user can then press the 'Calculate Donation Cost' button located below the 
dropdown menus, which presents him/her with an estimated cost of purchasing and shipping. Below the total cost appears a comparison of alternative provisions that relief organizations could purchase with a cash donation equal to the estimated total cost of purchasing and shipping the item the user has chosen. The GGDC illustrates that the value of items most frequently sent to disaster relief efforts by individual donors, measured in U.S. dollars, is usually less than the cost of shipping those items overseas. The calculator's comparison function also exposes the user to the ability of relief organizations to buy supplies in greater quantities at reduced prices by procuring them locally in the disaster-affected country, or through bulk purchasing. This demonstrates to the user that relief organizations can leverage monetary resources more effectively to serve a larger number of disaster-affected people than individual donors are able to by contributing in-kind.

The four items available for the user to choose from - a pair of jeans, 12 cans of tuna fish, 6 pack of half-liter water bottles, and teddy bear - were selected based on recommendations from CIDI and OFDA's logistics unit. Used clothing, bottled water, canned food, and sentimental toys represent some of the unsolicited materials most frequently donated to disaster relief efforts. The estimated cost of purchasing these items in the U.S., which the calculator reports to the user, is based on Walmart's listed retail price for an item matching the description of their selection. The calculator is programmed to present the user with an estimated cost of shipping derived from their choice of item, origin, and destination values by utilizing publically available FedEx shipping rates and calculations based on the size and weight of the goods. At the final stage of the project, CIDI's web designer integrated the core application into CIDI's website, and implemented a user interface consisting of three dropdown menus followed by a 'Calculate Donation Cost' button. 
GGDC users make selection from a list of four items commonly donated to disaster relief efforts, a point of origin in the U.S., and a disaster-affected destination city in one of ten countries as shown in Table 1. From those data points, the calculator informs the viewer how much the donation will cost to ship, and examples of what the same amount of money could purchase (e.g., drinkable water, blankets or hygiene kits) if donated directly to a relief organization in the disaster-affected country and how many disaster-effected people would be helped with that cash donation. Average local prices of drinkable water, blankets and hygiene kits in the disaster-affected country have been obtained from OFDA. Four origin cities Washington D.C., Miami, Chicago and Los Angeles - were chosen to represent a variety of U.S. population centers along with ten disaster-prone destination countries. Furthermore, the shortlist of four commonly donated items and the three alternative items that could be purchased in the disaster affected country with cash, were all compiled in consultation with the OFDA humanitarian experts who are regularly involved in disaster relief operations.

\section{Insert Table 1 here}

For example, assume Jane wants to send a teddy bear from her hometown Chicago to Tokyo, Japan. At the GGDC web site's drop down menus, she selects teddy bear out of the four commonly donated items, Chicago out of four origin cities and Tokyo / Japan out of ten disaster affected destination cities as shown in the Screenshot 1 of Figure 1. Once she clicks the "Calculate Donation Cost" button, the screen is updated with (i) cost of purchasing a teddy bear and directly shipping it to Tokyo - \$151.56, (ii) a local relief organization could buy 30,332 liters of clean water in Tokyo which would provide 15,166 people with 2 liters of drinking water for a 
day, or (iii) $\$ 151.66$ could also buy 22 blankets in Tokyo, and (iv) closing statement: "Save money. Save lives. Save the planet. Give Green", all shown in the Screenshot 2 of Figure 1.

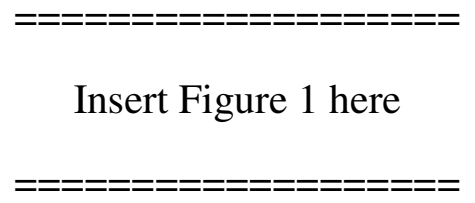

Alternatively when the donated item is either "6-pack of half-liter water bottles" or " 12 cans of tuna fish", the calculator replaces blankets with hygiene kits and displays the number of hygiene kits that could be purchased in the disaster-effected country together with the amount of clean water that could be purchased. For example, assume Jim wants to send "12 cans of tuna fish" from his hometown Washington DC to Manila, Philippines. He makes the item-origindestination choices as shown in the Screenshot 1 of Figure 2. Once he clicks the "Calculate Donation Cost" button, the screen is now updated with (i) cost of purchasing " 12 cans of tuna fish" and directly shipping it to Manila - $\$ 176.33$, (ii) a local relief organization could buy 35,266 liters of clean water in Manila which would provide 17,633 people with 2 liters of drinking water for a day, or (iii) $\$ 176.33$ could also buy 20 hygiene kits in Manila, as shown in the Screenshot 2 of Figure 2.

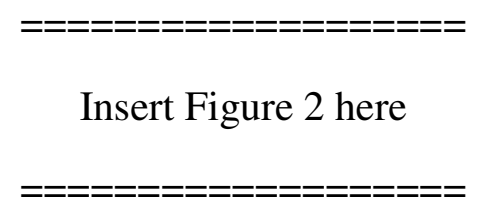

\subsection{GGDC's value}

Following the calculator's debut, feedback from donors and NGOs has been very positive concerning the potential for the GGDC as an effective learning tool. Specifically, we asked two 
professionals from humanitarian organizations to review the calculator: Julie Montgomery, the Director of Innovation and Learning at InterAction and Adam Runkle, Mass Care \& Logistics Manager at the American Red Cross (Greater Chicago Region).

InterAction is the largest coalition of U.S.-based NGOs working on international development and humanitarian response. As the Director of Innovation and Learning, Julie Montgomery is responsible for the creation of donor learning tools such as the NGO Aid Map, and has an extensive background in the use of technology for learning and impact. Supporting the GGDC's mission, she noted that it would be "useful for InterAction to help raise awareness with the general public on why cash donations are best." When asked if she thought the GGDC would be a useful tool for donors contributing to other member-organizations of InterAction, she remarked, "I think this tool would be very useful for their advocacy, marketing, and communications teams. I could see them using it to raise awareness with their individual donors." Finally, we asked her if, in her opinion, the GGDC effectively conveys to the user the educational message that monetary contributions to international disaster relief represent the most effective way for donors to contribute (as opposed to in-kind). She responded, "Yes, this tool does an excellent job in conveying that monetary contributions are more effective than inkind donations."

Adam Runkle found the GGDC to be "a terrific tool for finding the most intuitive and effective way to donate for international disasters." He noted that unsolicited material donations constitute "[a] highly prevalent issue during large-scale [humanitarian] responses (both domestic and international)", and that the calculator "will further enable donors to increase the size and reach of their contributions, yielding much higher results." Lastly, Adam commented on the importance of what the GGDC teaches the user: "Something aid organizations typically strive for 
is to spend donated funds locally during large-scale responses. Making purchases from local businesses and companies is an important step in helping the community as a whole recover from [a] disaster." The comparison function of the GGDC engages the user to consider the potential for relief organizations to procure supplies in the disaster-affected country at a much lower cost than would be possible in the U.S., while simultaneously assisting the local economy to recover. Feedback from both American Red Cross and InterAction has helped to affirm the potential of the GGDC as an effective learning tool for donors by virtue of its ability to educate users on key concepts of disaster relief and response that are largely unknown to the general public.

CIDI has pursued a media campaign to increase the calculator's exposure to the general public by securing placement for stories about the GGDC in newspapers such as Boston Globe, Providence Journal, Houston Chronicle, Indiana Republic and Massachusetts Sun. Two TV stations: WPRI-TV and EBRU-TV broadcasted stories featuring the GGDC in their evening news as well. In addition to having its own dedicated page, the GGDC is featured on other pages of USAID CIDI's website as an interactive item on the left side of each page on which it appears. Since April of 2013 the pages containing the GGDC received a combined 20,845 page views with 6,323 interactions occurring on the page specifically dedicated to the GGDC. The average interaction time with the GGDC lasts for just over 1 minute.

Though the general public's attention to issues concerning international disaster relief generally corresponds with mass media coverage following the onset of large-scale disasters, the GGDC provides the federal government and organizations working in disaster relief the opportunity to effectively engage donors in an educational capacity concerning the issue of donations. The GGDC informs users on some of the complexities associated with humanitarian 
supply chains, and the ineffective nature of unsolicited in-kind donations compared to monetary contributions when sent in response to international disasters.

\subsection{Limitations and future improvements}

The GGDC has some limitations and may be improved in a couple of ways. First, the user's interaction with the GGDC is limited. The user just selects one of the "item-origin-destination" options and then clicks the "Calculate Donation Cost" button. The user's engagement with the calculator lasts for approximately 1 minute unless the user tries another combination. A new design could offer more item choices and help users understand additional components of the humanitarian supply chain. Some of the choices could be specific to current disasters; bleach and plastic sheeting in light of the 2014 Ebola Virus Disease (EVD) epidemic in West Africa for example. This would keep the tool relevant to ongoing international disasters that donors may be interested in contributing to; increasing the likelihood of attracting new users. The GGDC could also be made more interactive and playable resulting in a tool that's more game-like. Another challenge of the calculator has been to attract users through social media platforms. Only 6,323 interactions on its dedicated page would suggest that many users of the calculator did not share their experience on social media. The new (more playable) design discussed above could improve user engagement and increase their motivation to share their experience on social media. The design of the calculator could include buttons for sharing the GGDC on Facebook, Twitter, Google+ and LinkedIn to facilitate the social media sharing behavior. Finally, we believe the decision-making process of donors and how the GGDC would fit into this process is worthy of more research. 
The GGDC's value to the humanitarian community and public could also be measured in other ways. Currently, two expert opinions are used to support the calculator's validity. In the future, different measures of success might be helpful. For example, a survey question could be asked to the users before they leave the site to measure learning. A good measure would probably be the conversion rate of people who use the site; i.e. ratio of the number of convinced users that unsolicited goods make more damage than good to the number of total users. Another avenue could be to promote the calculator in an email based donation campaign after a major international disaster and conduct $\mathrm{A} / \mathrm{B}$ split tests to statistically measure its impact on the outcome (donations).

\section{Concluding discussion}

Humanitarian supply chains are dynamic and complex systems with multiple interacting actors. There is often a delay between an action (e.g., donation) and outcome (e.g., relief). Moreover, the ambiguity and limited information availability might act as barriers to learning and individual or organizational donors find it challenging to understand the implications of their donations downstream in the supply chain. In this study, we introduce the GGDC to the humanitarian logistics community as a decision-aid tool to educate individual donors in smart compassion and allow them to experience the trade-offs.

Well-informed donors are frequently effective donors. Being well-informed includes understanding that every donation has an impact on relief organizations and survivors, and can be either beneficial, or deleterious to disaster relief operations. Experienced philanthropists contribute monetary donations to disaster relief operations because they understand that money is more versatile and more effective throughout all phases of disaster relief and recovery than are unsolicited material donations. The GGDC gives users a glimpse into the costly, complicated 
process that can attend receipt of unsolicited material donations, and demonstrates that what they choose to donate can impact survivors and relief efforts for good or ill.

The complex process necessary for an item to leave their hands and enter the hands of a disaster survivor are generally unknown to donors. When compounded by thousands of donors, such information gaps can lead to a "second disaster". Clogging the humanitarian supply chain with unsolicited material donations diminishes the ability of relief organizations to assist survivors quickly. Feelings of guilt or shame that come with enlightenment about donation impact, renders many donors unreceptive to straightforward messaging on this issue. For this reason, utilizing games and decision support tools such as the GGDC to raise public awareness in the cost and complexity of this process can be an effective way to deliver information on a sensitive subject in a fun, entertaining way. With the expectation of more frequent and devastating disasters in the future, partly due to global climate change (Braman et al., 2010), the GGDC and similar interactive tools carry the potential to help make better use of donations in improving humanitarian response to disasters. Hence, we recommend to the scholars and researchers in humanitarian logistics and supply chains to consider more games in educating the public, humanitarian workers and volunteers to improve the overall efficiency and effectiveness of humanitarian relief and development efforts.

\section{References}

Alexander, J. (2013), “Don't get upset when relief organizations use your donations for overhead", Slate Magazine, November 14, Available at: http://www.slate.com/articles/news_and_politics/foreigners/2013/11/how_typhoon_aid_o rganizations_spend_your_cash_donations.html (Accessed 11/26/2014)

Altay, N. (2008), “Issues in disaster-relief logistics. In M. Gad-el-Hak (ed)”, Large-Scale Disasters: Prediction, Control and Mitigation, Cambridge University Press, Cambridge, pp. 120-146. 
Balcik, B., Beamon, B.M. and Smilowitz, K. (2008), "Last Mile Distribution in Humanitarian Relief”, Journal of Intelligent Transportation Systems: Technology Planning and Operations, (12) 2, pp. 51-63.

Barta, B. and Bellman, E. (2005), "Sri Lanka is grateful, but what will they do with the ski parkas?", The Wall Street Journal, February 4.

Berckmans, P., Dawans, V., Schmets, G., Vandenbergh, D. and Autier, P. (1997), "Inappropriate Drug Donation Practices in Bosnia Herzegovina, 1992-1996", New England Journal of Medicine, Dec 18, 337(25), pp.1842-1845.

Besiou, M., Stapleton, O. and Van Wassenhove, L.N. (2011), "System dynamics for humanitarian operations", Journal of Humanitarian Logistics \& Supply Chain Management, 1(1), pp. 78-103.

Bowen, D.D. (1987), "A theory of experiential learning", Simulations \& Games, 18(2), pp. 192-206.

Braman, L.M., Suarez, P. and van Aalst, M.K. (2010), "Climate change adaptation: integrating climate science into humanitarian work", International Review of the Red Cross, 92(879), pp. 693-712.

Chomilier, B., Samii, R. and Van Wassenhove, L.N. (2003), "The Central Role of Supply Chain Management at IFRC", Forced Migration Review, 18, pp. 15-16.

Christopher, M. (2000), “The Agile Supply Chain: Competing in Volatile Markets”, Industrial Marketing Management, 29(1), pp. 27-34.

Cozzolino, A. (2012), "Humanitarian Logistics: Cross-Sector Cooperation in Disaster Relief Management", Springer.

Diani, H. (2006). "Help on the way for stuck tsunami aid", The Jakarta Post, January 14.

Forrester, J.W. (1961), Industrial Dynamics, MIT Press, Cambridge, MA

Fritz, C.E. and Mathewson, J.H. (1957), "Convergent behavior: a disaster control problem. Special Report for the Committee on Disaster Studies”, National Academy of Sciences. Disaster Study 9 476. N.R.C. National Academy of Sciences.

Fritz Institute (2005), "Lessons from the Tsunami: Survey of Non-Governmental Organizations in India and Sri Lanka", http://www.fritzinstitute.org/PDFs/findings/NGOsReport.pdf (accessed 11/26/2014).

Guha-Sapir, D., Hoyois, P. and Below, R. (2013), “Annual Disaster Statistical Review 2012”, The Numbers and Trends, Brussels: CRED.

Harteveld, C. (2011), Triadic Game Design: Balancing Reality, Meaning and Play, SpringerVerlag, London. 
Harteveld, C. and Bidarra, R. (2007), "Learning with games in a professional environment: A case study of a serious game about levee inspection", Proceedings of the $1^{\text {st }}$ learning with games, pp. 552-562.

Harvey, P. and Bailey, S. (2011), “Cash Transfer Programming in Emergencies”, Humanitarian Practice Network, Good Practice Review Number 11, (accessed 11/26/2014). http://www.odihpn.org/index.php?option=com _k2\&view=item\&layout=item\&id=3218

Holguin-Veras, J., Jaller, M., Van Wassenhove, L.N., Perez, N. and Wachtendorf, T. (2012), “On the unique features of post-disaster humanitarian logistics", Journal of Operations Management, 30, pp. 494-506.

Howlett, E., Kees, J. and Kemp, E. (2008), “The role of self-regulation, future orientation, and financial knowledge in long-term financial decisions", Journal of Consumer Affairs, 42(2), pp. 223-242.

Keys, J.B. (1989), “The management of learning grid for management development revisited", Journal of Management Development, 8(2), pp. 5-12.

Keys, J.B. and Wolfe, J. (1990), "The role of management games and simulations in education and research", Journal of Management, 16(2), pp. 307-336.

Kolb, D.A. (1984), "Experiential learning: experience as the source of learning and development", Prentice Hall, Englewood Cliffs, NJ.

Kovacs, G and Spens, K. (2011), "Trends and developments in humanitarian logistics: a gap analysis", International Journal of Physical Distribution \& Logistics Management, 41(1), pp. 32-45.

Lane, D.C. (1995), "On a resurgence of management simulations and games", Journal of the Operational Research Society, 46, 604-625.

Leung, G.M., Johnston, J.M., Tin, K.Y.K., Wong, I.O.L., Ho, L., Lam, W.W.T. and Lam, T. (2003), "Randomized controlled trial of clinical decision support tools to improve learning of evidence based medicine in medical students", British Medical Journal, 327(7423): pp. 1090-1095.

Lu, Q., Goh, M. and De Souza, R. (2013), "Learning mechanisms for humanitarian logistics", Journal of Humanitarian Logistics \& Supply Chain Management, 3(2), pp. 149-160.

McGonigal, J. (2011), "Reality Is Broken: Why Games Make Us Better and How They Can Change the World", the Penguin Press, New York.

Mentzer, J.T., DeWitt, W., Keebler, J. S., Min, S., Nix, N., Smith, C. D. and Zacharia, Z. G. (2001), "Defining Supply Chain Management", Journal of Business Logistics, 22(2), pp. 1-25. 
Newsweek (2002), “\$75 Million of Stuff”, February 18, pp. 62-63.

Oloruntoba, R. and Gray, R. (2006), “Humanitarian aid: an agile supply chain?”, Supply Chain Management: An International Journal, 11(2), pp.115-120.

Özpolat K.,Chen Y., Hales, D., Yu D. and Yalcin M. G., 2014. "Using Contests to provide Business Students Project-Based Learning in Humanitarian Logistics: PSAid Example", Decision Sciences Journal of Innovative Education, 12(4), 269-285

Protheroe, J., Nutbeam, D. \& Rowlands, G. (2009), "Health literacy: a necessity for increasing participation in health care", The British Journal of General Practice, 59(567): 721-723.

Stapleton, O., Van Wassenhove, L.N. and Tomasini, R. (2010), "The Challenges of Matching Corporate Donations to Humanitarian Needs and the Role of Brokers", Supply Chain Forum: an International Journal, 11(3), pp. 42-53.

Sydell, L. (2013), "For Advocacy Groups Video games Are The Next Frontier", NPR Blogs, Available at: http://www.npr.org/blogs/alltechconsidered/2013/11/29/247515389/foradvocacy-groups-video-games-are-the-next-frontier (Accessed 11/26/2014)

Tomasini, R.M. and Van Wassenhove, L.N. (2009), Humanitarian Logistics, London Palgrave Macmillan, Basingstoke.

Van Wassenhove, L.N. (2006), "Blackett Memorial Lecture. Humanitarian aid logistics: Supply Chain Management in high gear", Journal of the Operational Research Society, 57, pp. $475-489$.

Van Wassenhove, L.N., Martinez, A. J. and Stapleton, O. (2010), "An Analysis of the Relief Supply Chain in the First Week after the Haiti Earthquake", INSEAD Humanitarian Research Group, Available at: http://www.insead.edu/facultyresearch/centres/isic/documents/HaitiReliefSupplyChain_F inal25Jan_pdf, (Accessed 11/26/2014)

Zhou, Q. and Mayer, I. (2010) "Gaming as the method to integrate modelling and participatory approaches in Interactive Water Management", Proceedings of the International Environmental Modelling and Software Society 2010 International Congress on Environmental Modelling and Software, Modelling for Environment's Sake, Fifth Biennial Meeting, Ottawa, Canada. David A. Swayne, Wanhong Yang, A. A. Voinov, A. Rizzoli, T. Filatova (Eds.). Available at: http://repository.tudelft.nl/assets/uuid:2f21666616cd-4662-816c-f95ccf543876/293835.pdf (Accessed 11/26/2014) 